\title{
Why do I need research and theory? A guide for social workers
}

\author{
Jennifer Anderson-Meger, 2016 \\ Routledge, New York, NY \\ ISBN 987-1-138-83335-7, pp. 139, paperback, NZD49.97
}

\begin{abstract}
$\Lambda$
s a teacher of social work students, including supervising those

undertaking research projects, I
\end{abstract} found this short book very useful. I plan to use it with students to raise the topics of understanding the significance of how one learns (learning theory), and the importance of developing our personal epistemological belief system, in order to include research knowledge into critical social work decisionmaking. Our Bachelor of Social Work students undertake social science research practice papers, and independent research topics, involving searching the research literature, but some students seem to struggle with a personal connection between research and practice, and the requirement to be critical thinkers in their future social work decision-making. Personal epistemological beliefs and development are identified by Anderson-Meger (2016) as a base for undertaking lifelong learning; these provide ongoing social work practice competency as well as the core from which to defend actions and thinking processes throughout a professional social work career. While this text is aimed at social work students, it also provides excellent resources for teachers relating to critical thinking and the importance of research knowledge in social work practice.

The book is presented in six, well-referenced chapters that can be utilised as standalone chapters, or together as a congruent whole consideration of the importance of research and critical thinking, leadership for the future of the social work profession, learning theories, personal epistemological development, anxiety about learning, and practical suggestions for social work educators. The issues considered in each chapter are justified through linkages with the United States of America (USA) Council on Social Work Education's 2015 Education and Policy Accreditation Standards and the National Association of Social Workers Code of Ethics as applicable, but this also felt reasonably well connected to the Aotearoa New Zealand social work professional environment. Anderson-Meger (2016) has added quotes from her own research with social work students, integrating their voices which resonated and assisted with understanding and made the text very accessible. Each chapter finishes with a useful list of discussion questions which would assist students in developing their professional identity and responsibility while teaching social work decision-making or social science research.

Chapter One emphasises the importance of continuing professional development and use of research and critical thinking in order to be effective social workers holding generalist professional qualifications in an ever-changing world. Acknowledgment of personal bias is the starting point for critical self-reflection and an ability to practise effectively; the link between research method courses and critical thinking was made at the outset.

Chapter Two promotes the need for intellectual leadership in social work practice and research in order to provide the critical reflection and rigour required to solve challenges faced by our profession. Anderson-Meger (2016) highlights a 
number of leadership approaches including servant leadership, arguing that social work leadership is required to stimulate critically reflective, knowledge-informed or evidencebased practice grounded in social work values and ethics. The chapter includes a personal quiz on leadership preparation and ends with a range of discussion questions that promote reflection on leadership responsibilities for all social workers including social work students.

Chapter Three introduces learning theory and is well referenced providing direction for greater depth of focus. Clear links are made between considering learning theory and the application of learning by clients, social work practitioners, and our colleagues. The focus of the chapter is to promote individual understanding and reflection of how one best learns along with individual responsibility for on-going learning in order to be effective practitioners throughout our careers. The discussion questions focus the reader on their individual responsibility for consciously regulating their learning.

Chapter Four concentrates on the concept of epistemology and epistemological development, arguing that personal epistemology is a critical component in effective continuing learning and competent, knowledge-informed practice. A very useful questionnaire (using Likert scale choices) on epistemological beliefs has been adapted and developed by the author (pp. 89-92) which can be used for individual reflection and discussion about expanding knowledge beliefs including thinking about where knowledge comes from, the process for acquiring knowledge, and how knowledge is constructed.

Chapter Five provides a focus on the negative impact of anxiety on learning and suggests strategies to ensure this is considered along with individual coping mechanisms.

Chapter Six completes the text by providing excellent strategies and approaches for educators creating a learning environment that encourages critical thinking and epistemological development.

Overall, this book provides a very useful complement for both research methodology and social work decision-making texts. I found the book to be easy to read yet scholarly with excellent references and resources. I will use this coherent and logical text to strengthen my teaching about the importance of critically integrating research in social work practice, and the effects of beliefs and anxiety on learning. Discussions with students would readily be expanded to specifically include social work practice in the Aotearoa New Zealand context with linkages to the Aotearoa New Zealand Association of Social Worker's Code of Ethics and the New Zealand Social Workers Registration Board Core Competencies, Programme Recognition Standards, and Code of Conduct. The author of this very useful text is a professor and ethics fellow at Viterbo University, Wisconsin, USA. Her research focus is epistemology in social work and critical thinking. 